\title{
and of major bleeding in patients with atrial fibrillation and chronic kidney disease treated with and without warfarin
}

This article was published in the following Dove Press journal: International Journal of Nephrology and Renovascular Disease 14 October 2009

Number of times this article has been viewed

\author{
Hoang M Lai \\ Wilbert S Aronow \\ Phoenix Kalen \\ Sreedhar Adapa \\ Kaushal Patel \\ Arvind Goel \\ Ravi Vinnakota \\ Savneek Chugh \\ Renee Garrick \\ Divisions of General Medicine, \\ Nephrology, and Cardiology, \\ Department of Medicine, New York \\ Medical College, Valhalla, NY, USA
}

Correspondence: Wilbert S. Aronow Cardiology Division, New York Medical College, Macy Pavilion, Room 138 ,

Valhalla, NY 10595, USA

$\mathrm{Tel}+$ I 91449353 I I

Fax + I 9142356274

Emailwsaronow@aol.com

\begin{abstract}
The objective was to investigate the incidence of thromboembolic stroke in patients with chronic kidney disease (CKD) and atrial fibrillation (AF) treated with and without warfarin. We investigated the incidence of thromboembolic stroke and of major bleeding in 399 unselected patients with $\mathrm{CKD}$ and $\mathrm{AF}$ treated with warfarin to maintain an international normalized ratio (INR) between 2.0 and $3.0(\mathrm{~N}=232)$ and without warfarin $(\mathrm{N}=167)$. Of the 399 patients, $93(23 \%)$ were receiving hemodialysis, and $132(33 \%)$ had an estimated glomerular filtration rate (GFR) of $<15 \mathrm{~mL} / \mathrm{min} / 1.73 \mathrm{~m}^{2}$ At the 31-month follow-up of patients treated with warfarin and 23-month follow-up of patients not treated with warfarin, thromboembolic stroke developed in 21 of 232 patients $(9 \%)$ treated with warfarin and in 43 of 167 patients $(26 \%)$ not treated with warfarin $(P<0.001)$. Major bleeding occurred in 32 of 232 patients $(14 \%)$ treated with warfarin and in 15 of 167 patients $(9 \%)$ not treated with warfarin ( $P$ not significant). Stepwise Cox regression analysis showed that significant independent predictors of thromboembolic stroke were use of warfarin (odds ratio, $0.28 ; P<0.0001$ ) and prior stroke or transient ischemic attack (odds ratio, $2.9 ; P<0.05$ ). In conclusion, this observational study showed that CKD patients with AF treated with warfarin to maintain an INR between 2.0 and 3.0 had a significant reduction in thromboembolic stroke and an insignificant increase in major bleeding.
\end{abstract}

Keywords: chronic kidney disease, atrial fibrillation, anticoagulants, thromboembolic stroke, major bleeding

\section{Introduction}

Chronic kidney disease (CKD) is associated with an increased prevalence and incidence of atrial fibrillation (AF). ${ }^{1-6}$ The prevalence of AF in persons with CKD was $7 \%,{ }^{1} 11 \%,{ }^{2} 14 \%,{ }^{3} 19 \%,{ }^{4} 23 \%,{ }^{5}$ and $27 \%{ }^{6}$ Vazquez and colleagues reported that 26 of 190 hemodialysis patients (14\%) had AF at baseline. ${ }^{3}$ At one-year follow-up, AF was the only independent predictor of thromboembolic events (odds ratio [OR], 8.03; 95\% confidence interval [CI]: 2.35-27.4). ${ }^{3}$ During the 50-month follow-up, Vazquez and colleagues reported that 11 of the 26 patients $(42.3 \%)$ with AF had 14 thromboembolic events while thromboembolic events occurred in $9.7 \%$ of the 164 patients with sinus rhythm at baseline (relative risk [RR], 4.6; 95\% CI: 2.4-8.6) in unadjusted analyses. ${ }^{7}$ During a mean follow-up period of 47 months, 20 of the 164 hemodialysis patients (12\%) without AF at baseline developed AF. Those who developed AF had a significant increase in subsequent thromboembolic events (RR, 5.2; 95\% CI: $2.1-12.4){ }^{8}$ 
In the general population, numerous prospective, randomized, double-blind, placebo-controlled trials ${ }^{9-18}$ and prospective, nonrandomized observational data ${ }^{19-21}$ have shown that high-risk patients with nonvalvular AF treated with warfarin to maintain an international normalized ratio (INR) between 2.0 and 3.0 have a significant decrease in thromboembolic stroke with an acceptable risk of bleeding. ${ }^{9-21}$ At 1.1-year follow-up in the Stroke Prevention and Atrial Fibrillation (SPAF) Study III, patients with $\mathrm{AF}$ considered to be at high risk for developing new thromboembolic stroke who were randomized to treatment with oral warfarin to achieve an INR between 2.0 and 3.0 had a $72 \%$ significant decrease in ischemic stroke or systemic embolism compared with patients randomized to treatment with oral aspirin $325 \mathrm{mg}$ daily plus oral warfarin to achieve an INR between 1.2 and 1.5. ${ }^{11}$ Adjusted-dose warfarin caused an absolute decrease in ischemic stroke or systemic embolism of $6.0 \%$ per year. ${ }^{11}$

However, all of these clinical trials ${ }^{8-21}$ have excluded patients with late-stage CKD. It is essential that prospective, double-blind, placebo-controlled trials be performed in patients with late-stage $\mathrm{CKD}$ and $\mathrm{AF}$ to determine the efficacy of oral anticoagulant therapy in preventing thromboembolic events and the incidence and type of hemorrhagic events. ${ }^{22}$ The present study reports a retrospective analysis of the incidence of thromboembolic stroke and of major bleeding in 399 patients with CKD and AF treated with warfarin to maintain an INR between 2.0 and 3.0 (232 patients) versus no warfarin (167 patients) by the nephrologists at Westchester Medical Center/New York Medical College.

\section{Methods}

In an observational retrospective study, we reviewed all charts for the incidence of thromboembolic events and of major bleeding in all patients with CKD and nonvalvular AF treated with and without warfarin by the nephrologists at Westchester Medical Center/New York Medical College. No patients were excluded from the analysis. Of the 399 patients with CKD, 93 (23\%) were receiving hemodialysis, $132(33 \%)$ had an estimated glomerular filtration rate $(\mathrm{GFR})<15 \mathrm{~mL} / \mathrm{min} / 1.73 \mathrm{~m}^{2}, 67$ (17\%) had an estimated GFR between $15-29 \mathrm{~mL} / \mathrm{min} / 1.73 \mathrm{~m}^{2}$, and $200(50 \%) \mathrm{had}$ an estimated GFR between $30-59 \mathrm{~mL} / \mathrm{min} / 1.73 \mathrm{~m}^{2}$. The estimated GFR was calculated by the Modification of Diet in Renal Disease study equation. ${ }^{23,24}$ The charts were also analyzed for all of the variables listed in Table 1.

The dose of warfarin used was adjusted to maintain an INR between 2.0 and 3.0. The dose of aspirin used was 81 mg daily.

Table I Baseline characteristics for patients with chronic kidney disease and atrial fibrillation treated with and without warfarin

\begin{tabular}{|c|c|c|c|}
\hline Variable & Warfarin $(\mathbf{N}=232)$ & No warfarin $(N=167)$ & $P$ value \\
\hline Women & $67(29 \%)$ & $61(37 \%)$ & Not significant \\
\hline Men & 165 (7I\%) & $106(63 \%)$ & Not significant \\
\hline Age (years) & $73 \pm 12$ & $77 \pm 11$ & $<0.001$ \\
\hline GFR $30-59 \mathrm{~mL} / \mathrm{min} / 1.73 \mathrm{~m}^{2}$ & II 5 (50\%) & 85 (5।\%) & Not significant \\
\hline GFR I5-29 mL/min/l.73 $\mathrm{m}^{2}$ & $39(17 \%)$ & $28(17 \%)$ & Not significant \\
\hline GFR $<15 \mathrm{~mL} / \mathrm{min} / 1.73 \mathrm{~m}^{2}$ & 78 (34\%) & $54(32 \%)$ & Not significant \\
\hline Hemodialysis & $5 \mathrm{I}(22 \%)$ & $42(25 \%)$ & Not significant \\
\hline Renal transplant & $15(6 \%)$ & $5(3 \%)$ & Not significant \\
\hline Aspirin & $92(40 \%)$ & $73(44 \%)$ & Not significant \\
\hline Prior stroke or TIA & $19(8 \%)$ & $13(8 \%)$ & Not significant \\
\hline Coronary artery disease & 145 (63\%) & $103(62 \%)$ & Not significant \\
\hline Valvular heart disease & $46(20 \%)$ & $23(14 \%)$ & Not significant \\
\hline Peripheral arterial disease & $15(6 \%)$ & 19 (II\%) & Not significant \\
\hline Smoking & $64(28 \%)$ & $42(25 \%)$ & Not significant \\
\hline Hypertension & 148 (64\%) & II 4 (68\%) & Not significant \\
\hline Diabetes mellitus & $108(47 \%)$ & 66 (40\%) & Not significant \\
\hline Dyslipidemia & $156(67 \%)$ & $109(65 \%)$ & Not significant \\
\hline Follow-up (months) & $31 \pm 34$ & $23 \pm 30$ & $<0.01$ \\
\hline
\end{tabular}

Abbreviations: GFR, estimated glomerular filtration rate; TIA, transient ischemic attack. 
Student's $t$-tests were used to analyze continuous variables between the warfarin and no warfarin groups. Chi-squared tests and Fisher's exact tests were used to analyze dichotomous variables between the warfarin and no warfarin groups. Stepwise Cox regression analysis was performed for thromboembolic stroke using all of the variables listed in Table 1.

The institutional review boards of Westchester Medical Center and of New York Medical College approved this study.

\section{Results}

Table 1 lists 18 variables for patients treated with and without warfarin. Table 1 also lists levels of statistical significance.

Table 2 shows the incidence of thromboembolic stroke and of major bleeding in patients treated with and without warfarin. Table 2 also lists levels of statistical significance. No thromboembolic events other than thromboembolic stroke were observed during this study. Of the 21 thromboembolic strokes that occurred on warfarin, nine $(43 \%)$ occurred when the INR was $<2.0$. Computed tomographic brain scans or magnetic resonance imaging were performed in 60 of the 64 thromboembolic strokes (94\%) diagnosed clinically and confirmed the presence of thromboembolic stroke in 60 of 60 patients (100\%). Computed tomographic brain scans or magnetic resonance imaging also showed that 14 other patients had intracerebral bleeding.

Table 3 shows the stepwise Cox regression analysis for thromboembolic stroke. Significant independent predictors of thromboembolic stroke were prior stroke or transient ischemic attack $(\mathrm{OR}=2.9)$ and use of warfarin $(\mathrm{OR}=0.28)$.

Table 4 shows the incidence of thromboembolic stroke for patients treated with and without warfarin who were receiving hemodialysis, who had an estimated GFR $<15 \mathrm{~mL} / \mathrm{min} / 1.73 \mathrm{~m}^{2}$, who had an estimated GFR between $15-29 \mathrm{~mL} / \mathrm{min} / 1.73 \mathrm{~m}^{2}$, and who had an estimated GFR between $30-59 \mathrm{~mL} / \mathrm{min} / 1.73 \mathrm{~m}^{2}$. Table 4 also lists levels of statistical significance.
Table 2 Incidence of thromboembolic stroke and of major bleeding during follow-up of patients with chronic kidney disease with atrial fibrillation treated with and without warfarin

\begin{tabular}{llll}
\hline Variable & $\begin{array}{l}\text { Warfarin } \\
(\mathbf{N}=\mathbf{2 3 2})\end{array}$ & $\begin{array}{l}\text { No warfarin } \\
\mathbf{( N = 1 6 7 )}\end{array}$ & P value \\
\hline New stroke & $21(9 \%)$ & $43(26 \%)$ & $<0.001$ \\
Major bleeding & $32(14 \%)$ & $15(9 \%)$ & Not significant \\
\hline
\end{tabular}

Table 5 shows the types of major bleeding episodes in patients treated with and without warfarin. No significant differences were found between the two groups.

\section{Discussion}

In an observational study of patients with $\mathrm{AF}$ and a high proportion of CKD undergoing percutaneous coronary intervention with stent implantation, age $(P<0.01)$ and nonanticoagulation $(P=0.02)$ were independent predictors of death, acute myocardial infarction, or target vessel revascularization in patients with $\mathrm{AF}^{25}$ However, there was a borderline significant finding that persons with chronic renal failure (undefined by the authors) were less likely to be anticoagulated at discharge, making it difficult to draw any conclusions regarding patients with CKD from this paper. ${ }^{25}$

In an observational study analyzing US Renal Data Service DMMS Wave (Dialysis Morbidity and Mortality Wave 2 Study) data, 123 persons were hospitalized for AF, and $90(73 \%)$ died by the 2.92-year follow-up. ${ }^{26}$ Among these persons, only use of warfarin and systolic blood pressure higher than $130 \mathrm{~mm} \mathrm{Hg}$ were associated with increased survival.

Many physicians consider CKD a condition that causes a high risk of bleeding complications in patients given warfarin for $\mathrm{AF}$ and are unwilling to prescribe warfarin for this indication. ${ }^{27}$ However, this viewpoint has been challenged. ${ }^{28-30}$ In a small study of hemodialysis patients followed for 20 months, hemorrhagic events occurred in $31 \%$ of 29 patients (seven with $\mathrm{AF}$ ) receiving oral anticoagulants and $14 \%$ of 211 patients not receiving oral anticoagulants. ${ }^{29}$ None of the patients receiving oral

Table 3 Stepwise cox regression analysis for thromboembolic stroke

\begin{tabular}{llllll}
\hline Parameter & Coefficient & Standard error & P value & Odds ratio & 95\% Confidence interval \\
\hline Warfarin & -1.2765 & 0.2927 & $<0.0001$ & 0.2790 & $0.1572,0.4952$ \\
Prior stroke or TIA & 1.0566 & 0.4277 & $<0.05$ & 2.8766 & $1.2439,6.6520$ \\
\hline
\end{tabular}

Abbreviation: TIA, transient ischemic attack. 
Table 4 Incidence of thromboembolic stroke for different glomerular filtration rates and for hemodialysis patients treated with and without warfarin

\begin{tabular}{|c|c|c|c|}
\hline Variable & Warfarin & No warfarin & $P$ value \\
\hline Hemodialysis patients & $5 / 51(10 \%)$ & $16 / 42(38 \%)$ & $<0.005$ \\
\hline GFR $<15 \mathrm{~mL} / \mathrm{min} / 1.73 \mathrm{~m}^{2}$ & $8 / 78(10 \%)$ & $20 / 54(37 \%)$ & $<0.00$ I \\
\hline GFR I5-29 mL/min/ $/ .73 \mathrm{~m}^{2}$ & $2 / 39(5 \%)$ & $6 / 28(21 \%)$ & $<0.05$ \\
\hline GFR $30-59 \mathrm{~mL} / \mathrm{min} / 1.73 \mathrm{~m}^{2}$ & $1 \mathrm{I} / \mathrm{II}$ (10\%) & I7/85 (20\%) & $<0.05$ \\
\hline
\end{tabular}

Abbreviation: GFR, estimated glomerular filtration rate.

anticoagulants developed a fatal hemorrhage, intracranial hemorrhage, or serious clinical sequelae. ${ }^{29}$ In a review of warfarin use in hemodialysis patients, Elliott and colleagues noted major bleeding rates varying from 0.1 to 0.54 events per patient-year of warfarin exposure and stressed that the true bleeding risk associated with the use of warfarin in hemodialysis patients remains unknown, given the reliance on small observational studies with potential confounding by comorbid conditions. ${ }^{31}$

Quinn and colleagues examined the issue of anticoagulation for AF of hemodialysis patients in a cost-utility analysis. ${ }^{32}$ At a threshold of $\$ 100,000$ per quality-adjusted life-year, the probabilities that no therapy, aspirin, or warfarin was the most efficient therapy were $20 \%, 23 \%$, and $58 \%$, respectively. ${ }^{32}$ An editorial accompanying this paper recommended that until more data are available, anticoagulation should be considered in hemodialysis patients with AF, adhering to screening and monitoring as in the general population. $^{33}$

The data from the present observational study of 399 unselected patients with CKD and AF including 93 patients on hemodialysis and 132 with an estimated GFR $<15 \mathrm{~mL} / \mathrm{min} / 1.73 \mathrm{~m}^{2}$ showed that the incidence of new thromboembolic stroke was $9 \%$ at 31-month follow-up for 232 patients treated with warfarin and $26 \%$ at 23 -month follow-up for 167 patients not treated with warfarin $(P<0.001)$. Stepwise Cox regression analysis showed that significant independent predictors of new thromboembolic stroke were prior stroke or transient ischemic attack (OR, 2.9; 95\% CI: 1.2-6.6) and use of warfarin (OR, 0.28; 95\% CI: 0.16-0.50). Warfarin significantly reduced the incidence of new thromboembolic stroke in patients receiving hemodialysis $(10 \%$ versus $38 \%)(P<0.005)$, in patients with an estimated GFR $<15 \mathrm{~mL} / \mathrm{min} / 1.73 \mathrm{~m}^{2}$ $(10 \%$ versus $37 \%)(P<0.001)$, in patients with an estimated GFR of $15-29 \mathrm{~mL} / \mathrm{min} / 1.73 \mathrm{~m}^{2}$ (5\% versus $21 \%$ ) $(P<0.05)$, and in patients with an estimated GFR of $30-59 \mathrm{~mL} / \mathrm{min} / 1.73 \mathrm{~m}^{2}(10 \%$ versus $20 \%)(P<0.05)$.

The data from the present study also showed that episodes of major bleeding occurred in 32 of 232 patients $(14 \%)$ treated with warfarin versus 15 of 167 patients $(9 \%)$ not treated with warfarin ( $P$ not significant). The types of major bleeding episodes were not significantly different between patients treated with and without warfarin.

The major limitation of this study is that it was not a prospective, randomized, double-blind, placebo-controlled study investigating the incidence of thromboembolic stroke and of major bleeding in patients with CKD and AF treated with warfarin versus placebo. Because of the high prevalence of AF and its association with an increased incidence of thromboembolic events in patients with late-stage CKD, it is essential that prospective, randomized, double-blind, placebo-controlled trials be performed in these patients to determine the efficacy of oral anticoagulant therapy in preventing thromboembolic events and the incidence and type of hemorrhagic events. Data from the present observational study favor treating patients with CKD and AF including those with late-stage CKD with warfarin on an individual basis, taking into account both the thromboembolism risk as well as the hemorrhagic risk.

Table 5 Types of major bleeding episodes in patients treated with and without warfarin

\begin{tabular}{llll}
\hline Major bleeding episode & Warfarin $(\mathbf{N}=\mathbf{3 2})$ & No warfarin $(\mathbf{N}=\mathbf{I 5})$ & $\mathbf{P}$ value \\
\hline Transfusion for gastrointestinal bleeding & I I (34\%) & $6(40 \%)$ & Not significant \\
Intracerebral bleeding & I I (34\%) & $3(20 \%)$ & Not significant \\
Transfusion for hemoptysis & $3(9 \%)$ & $0(0 \%)$ & Not significant \\
Transfusion for retroperitoneal hematoma & $3(9 \%)$ & I (7\%) & Not significant \\
Transfusion for intraperitoneal bleeding & $2(6 \%)$ & $0(0 \%)$ & Not significant \\
Transfusion for bleeding of unknown cause & $2(6 \%)$ & $3(20 \%)$ & Not significant \\
Transfusion for abdominal wall hematoma & $0(0 \%)$ & I (7\%) & Not significant \\
Transfusion for pelvic hemorrhage & $0(0 \%)$ & I (7\%) & Not significant \\
\hline
\end{tabular}




\section{Disclosures}

None of the authors have any conflicts of interest pertaining to this article.

\section{References}

1. Abe S, Yoshizawa M, Nakanishi N, et al. Electrocardiographic abnormalities in patients receiving hemodialysis. Am Heart J. 1996; 131:1137-1144.

2. Atar I, Konas D, Acikel S, et al. Frequency of atrial fibrillation and factors related to its development in dialysis patients. Int $J$ Cardiol. 2006;106:47-51.

3. Vazquez E, Sanchez-Perales C, Borrego F, et al. Influence of atrial fibrillation on the morbido-mortality of patients on hemodialysis. Am Heart J. 2000;140:886-890.

4. Das M, Aronow WS, McClung JA, Belkin RN. Increased prevalence of coronary artery disease, silent myocardial ischemia, complex ventricular arrhythmias, atrial fibrillation, left ventricular hypertrophy, mitral annular calcium, and aortic valve calcium in patients with chronic renal insufficiency. Cardiol Rev. 2006;14:14-17.

5. Fabbian F, Catalano C, Lambertini D, et al. Clinical characteristics associated to atrial fibrillation in chronic hemodialysis patients. Clin Nephrol. 2000;54:234-239.

6. Genovesi S, Pogliani D, Faini A, et al. Prevalence of atrial fibrillation and associated factors in a population of long-term hemodialysis patients. Am J Kidney Dis. 2005;46:897-902.

7. Vazquez E, Sanchez-Perales C, Lozano C, et al. Comparison of prognostic value of atrial fibrillation versus sinus rhythm in patients on long-term hemodiálysis. Am J Cardiol. 2003;92:868-871.

8. Vazquez-Ruiz de Castroviejoa E, Sanchez-Perales C, LozanoCabezas C, et al. [Incidence of atrial fibrillation in hemodialysis patients. A prospective long-term follow-up study]. Rev Esp Cardiol. 2006;59:779-784.

9. The effect of low-dose warfarin on the risk of stroke in patients with nonrheumatic atrial fibrillation. The Boston Area Anticoagulation Trial for Atrial Fibrillation Investigators. N Engl J Med. 1990;323:1505-1511.

10. Risk factors for stroke and efficacy of antithrombotic therapy in atrial fibrillation. Analysis of pooled data from five randomized controlled trials. Arch Intern Med. 1994;154:1449-1457.

11. Adjusted-dose warfarin versus low-intensity, fixed-dose warfarin plus aspirin for high-risk patients with atrial fibrillation: Stroke Prevention in Atrial Fibrillation III randomised clinical trial. Lancet. 1996;348: 633-638.

12. Secondary prevention in non-rheumatic atrial fibrillation after transient ischaemic attack or minor stroke. EAFT (European Atrial Fibrillation Trial) Study Group. Lancet. 1993;342:1255-1262.

13. Peterson P, Boysen G, Godtfredsen J, et al. Placebo-controlled, randomised trial of warfarin and aspirin for prevention of thromboembolic complications in chronic atrial fibrillation. Lancet. 1989;1:175-179.

14. Preliminary report of the Stroke Prevention in Atrial Fibrillation Study. N Engl J Med. 1990;322:863-868.

15. Stroke Prevention in Atrial Fibrillation Study. Final results. Circulation. 1991;84:527-539.

16. Connolly SJ, Laupacis A, Gent M, et al. Canadian Atrial Fibrillation Anticoagulation (CAFA) Study. J Am Coll Cardiol. 1991;18:345-355.
17. Ezekowitz MD, Bridgers SL, James KE, et al. Warfarin in the prevention of stroke associated with nonrheumatic atrial fibrillation. $N$ Engl J Med. 1992;327:1406-1412.

18. Warfarin versus aspirin for prevention of thromboembolism in atrial fibrillation: Stroke Prevention in Atrial Fibrillation II Study. Lancet. 1994;343:687-691.

19. Gullov AL, Koefoed BG, Petersen P, et al. Fixed minidose warfarin and aspirin alone and in combination vs adjusted-dose warfarin for stroke prevention in atrial fibrillation. Second Copenhagen Atrial Fibrillation, Aspirin, and Anticoagulation Study. Arch Intern Med. 1998;158:1513-1521.

20. Aronow WS, Ahn C, Kronzon I, Gutstein H. Incidence of new thromboembolic stroke in persons $\geq 62$ years old with chronic atrial fibrillation treated with warfarin versus aspirin. J Am Geriatr Soc. 1999;47:366-368.

21. Aronow WS, Ahn C, Kronzon I, Gutstein H. Effect of warfarin versus aspirin on the incidence of new thromboembolic stroke in older persons with chronic atrial fibrillation and abnormal and normal left ventricular ejection fraction. Am J Cardiol. 2000;85:1033-1035.

22. Aronow WS. Acute and chronic management of atrial fibrillation in patients with late-stage CKD. Am J Kidney Dis. 2009;53:701-710.

23. Levey AS, Bosch JP, Lewis JB, et al. A more accurate method to estimate glomerular filtration rate from serum creatinine. A new predictive equation. Ann Intern Med. 1999;130:461-470.

24. National Kidney Foundation: Kidney Disease Outcome Quality Initiative (K/DOQI) clinical practice guidelines for chronic kidney disease: Evaluation, classification, and stratification. Am J Kidney Dis. 2002;39(suppl 1):S1-S266.

25. Ruioz-Nodar JM, Marin F, Hurtado JA, et al. Anticoagulant therapy use in 426 patients with atrial fibrillation undergoing percutaneous coronary intervention and stent implantation. $\mathrm{J} \mathrm{Am} \mathrm{Coll} \mathrm{Cardiol.}$ 2008;51:818-835.

26. Abbott KC, Trespalacios FC, Taylor AJ, Agodoa LY. Atrial fibrillation in chronic dialysis patients in the United States: risk factors for hospitalization and mortality. BMC Nephrol. 2003;4:1.

27. Korantzopoulos P, Kokkoris S, Liu T, Protopsaltis I, Li G, Goudevenos JA. Atrial fibrillation in end-stage renal disease. Pacing Clin Electrophysiol. 2007;30:1391-1397.

28. Fuster V, Ryden LE, Asinger RW, et al. ACC/AHA/ESC guidelines for the management of patients with atrial fibrillation: Executive summary. J Am Coll Cardiol. 2001;38:1231-1265.

29. Vazquez E, Sanchez-Perales C, Garcia-Cortes J, et al. Ought dialysis patients with atrial fibrillation be treated with oral anticoagulants? Int J Cardiol. 2003;87:135-139.

30. Wright JR, Kalra PA. Ought dialysis patients with atrial fibrillation be treated with oral anticoagulants? Int J Cardiol. 2003;87: 139-141.

31. Elliott MJ, Zimmerman D, Holden RM. Warfarin anticoagulation in hemodialysis patients: A systematic review of bleeding rates. $\mathrm{Am} \mathrm{J}$ Kidney Dis. 2007;50:433-440.

32. Quinn RR, Naimark DM, Oliver MJ, et al. Should hemodialysis patients undergo systemic anticoagulation? A cost-utility analysis. Am J Kidney Dis. 2007;50:421-432.

33. Abbott KC, Neff RT, Bohen EM, Narayan R. Anticoagulation for chronic atrial fibrillation in hemodialysis patients: which fruit from the decision tree? Am J Kidney Dis. 2007;50:345-348.

\section{Publish your work in this journal}

The International Journal of Nephrology and Renovascular Disease is an international, peer-reviewed open-access journal focusing on the pathophysiology of the kidney and vascular supply. Epidemiology, screening, diagnosis, and treatment interventions are covered as well as basic science, biochemical and immunological studies. The journal welcomes original

\section{Dovepress}

research, clinical studies, reviews \& evaluations, expert opinion and commentary, case reports and extended reports. The manuscript management system is completely online and includes a very quick and fair peerreview system, which is all easy to use. Visit http://www.dovepress.com/ testimonials.php to read real quotes from published authors. 